\title{
History and development of the Liver Unit
}

\author{
I G McFarlane, A L W F Eddleston, P M Smith, R P H Thompson
}

History does not record whether the mandarins of King's College Hospital and Medical School fully appreciated what they were doing when, in 1966, they appointed Roger Williams as consultant physician and medical tutor after his brief period as consultant at Southampton General Hospital. As a former disciple of Sheila Sherlock at the Royal Free Hospital he had not surprisingly developed some knowledge of hepatology and, from the outset, his intention at King's was to improve the clinical care of patients with liver disease through the setting up of a Unit in which research groups of basic and applied scientists would work closely with the clinicians. It is unlikely that, at the time, anyone could have forseen the success that he would achieve in this objective.

The Unit began modestly enough on 1 August that year with the arrival of an ancient and battered Vauxhall estate car driven by Paul Smith, Roger's first clinical research fellow, who had come with him from Southampton along with a technician, Frances Studley. From the back of this car, a centrifuge, a colorimeter and assorted glassware were transferred to a small laboratory in a room off the lower clinical corridor that had been loaned by the then professor of medicine, John Anderson. The equipment was carefully arranged to await the arrival of Roger, who had commandeered Paul's more reliable Volkswagen a week earlier. The first laboratory inspection took place that afternoon. The staff were ordered immediately to rearrange the equipment in different cupboards - thereby establishing a pattern of interest in even the minutest aspects of the Unit's operations, that has persisted to the present day.

There followed a period of settling in, when new friends were made, and some unpleasant truths came to light - only four of the 24 allocated beds were actually at King's, the remainder being at Dulwich Hospital a couple of miles away. Nevertheless, patients with liver problems began to appear in increasing numbers and the beds at King's strangely multiplied, with a corresponding and equally mysterious reduction in the numbers at Dulwich. Work on iron metabolism and haemochromatosis, Roger's main earlier interest, continued - assisted by the Radiological Protection Services' whole body counter at Sutton, Surrey. The first paper from the Unit soon appeared in the Lancet. ${ }^{\prime}$

The firm became popular with the students, who were initially shared with the cardiologist Sam Oram. Some of these early students, such as Brian Gazzard and Steve Wilkinson, were, faute de mieux, later to become research fellows on the Unit. At the beginning of 1967 Peter Toghill was appointed Roger's first full senior registrar, bringing with him knowledge of splenic disorders which was to prove useful when Laurie Blendis arrived shortly after as a second research fellow to work on haemodynamics. Richard Thompson followed nine months later to take on bilirubin metabolism, in collaboration with Charles Gray of the Department of Chemical Pathology.

The unbelievably cramped conditions in that first laboratory were undoubtedly hazardous, but they did generate a closeness among the research fellows that led to lasting friendships, and which is a feature of the Unit even today. The early interest in haemochromatosis soon expanded into the physiology and complications of cirrhosis, and broadened further with increasing referrals of patients with all forms of liver disease. Adrian Eddleston, after a stint as clinical registrar, began his long and fruitful interest in immunology.

The professor of medicine, perhaps suspecting that he had a cuckoo in his nest, found that he needed his laboratory after all and the group moved to (only slightly) larger accommodation in what had been the delivery suite adjacent to Todd Ward (formerly an obstetrics ward) on the second floor. Roger's office, shared with a fearsome secretary acquired along the way, was set up in the former sluice room, with files fitting neatly into the bedpan racks. Discussions took place in the broom cupboard.

The first major impetus was provided by the Medical Research Council in 1968 with the establishment of an MRC Group within the Unit for studies into the Metabolism and Haemodynamics of Liver Disease. In that year also a link with Roy Calne and his team in Cambridge was established that led to the performance of the first liver transplants in the United Kingdom.

With the development of hepatology, Todd ward was increasingly used for liver patients to the point where, in 1970, it was converted to the main liver ward. This coincided with the start of a cooperative venture between the Liver Unit and the Department of Child Health at King's, initiated by the appointment of Alex Mowat as consultant paediatrician with an interest in liver disease, and later (in 1973) a consultant surgeon, Ted Howard, who had trained in paediatric surgery at Great Ormond Street.

In 1971, with the assistance of The Wellcome Trust, the MRC, the King's College Hospital Voluntary Research Trust and several other charitable and private donations, construction began on a new laboratory complex on the roof of Todd ward. This complex, comprising some $750 \mathrm{~m}^{2}$ of laboratory and other facilities, was opened on 16 February, 1972 by HRH The Duchess of Gloucester.

The building of the new laboratories not only provided improved resources for research and development, and laboratory support for the management of liver patients in the ward below, but also allowed for conversion of the old laboratory area into a two bed specialist 'Liver 
Failure Unit', which was was formally opened by the Rt Hon Lord Aberdare, Minister of State, on 18 May, 1973. This facility, the first of its kind in the world, was made possible through central funding from the Department of Health (prompted by increasing concern over outbreaks of hepatitis among staff and patients in renal dialysis units) and marked the start of the Liver Unit's conversion to a supraregional referral centre.

After an independent MRC review at the start of the 1972-77 quinquennium, which highly commended the work, the Medical School took over responsibility for the Liver Unit with the three lectureships in clinical medicine and three lectureships in biochemistry that had been funded by the MRC. Thus was the Academic Unit in Liver Disease established, thereby not only ensuring its future stability but also providing the Medical School with additional staff to assist with the teaching of medical students and with the postgraduate training of clinicians and basic scientists in liver disease.

This was followed by a period of consolidation of the clinical and academic activities of the Unit. Support from the MRC continued in the form of a major programme grant for research into acute liver failure. Additional project grants were awarded by the MRC, as well as by The Wellcome Trust, the Nuffield Foundation, and other major research grant bodies. Support was also received from many private benefactors and, in 1973 , these funds were consolidated into a registered charity known as the Liver Research Unit Trust under the Chairmanship of The Lord Goodman.

In 1975, a university senior lectureship awarded by The Wellcome Trust to Adrian Eddleston in recognition of his contribution to, and the Unit's long standing interest in, the study of immune mechanisms in liver disease was formally taken over by the Medical School, with the conferment in 1982 of a personal chair in liver immunology.

In 1979, the South East Thames Regional Health Authority (SETRHA) formally recognised adult liver care at King's as a regional specialty - one of the first to be set up in this way. This was a time of rapid development in the Unit. It saw the opening of a new laboratory by HRH Princess Alexandra, the Sheik Zaid Centre, which was made possible by a donation from the Government of the United Arab Emirates. This doubled the previous laboratory facilities and enabled expansion of the Unit's research on cancer of the liver and pancreas. In addition, recognising the increasing contribution of the Unit's laboratory activities to routine patient care, SETRHA took the unusual step of establishing liver histopathology and hepatitis virology as dedicated services within the Unit. These formed the nucleus for the later expansion of the specialist laboratory based services, in keeping with Roger's original aim to provide a strong scientific base to support both the research activities and the clinical management of the patients.

Bernard Portmann was appointed as consultant histopathologist and Ian McFarlane as consultant biochemist. The histology section became The Sir Max Aitken Laboratory Suite in tribute to the Beaverbrook Foundation's long standing and generous support.

During this period, the paediatric liver service was also expanding - leading to the establishment of the Variety Club Children's Hospital for specialist care of children with liver disease, which was opened by HRH Princess Anne in 1983. The siting of this facility adjacent to the adult Liver Unit has reinforced the cooperation in the care of liver disease patients of all ages. In 1984, a joint application by Roger Williams and Alex Mowat for National Recognition and Funding of the specialty at King's was a stimulus that led the Department of Health to set up the Supraregional Advisory Board to consider this and applications by other specialties for similar recognition.

One of the long standing interests in the Liver Unit has been the treatment of bleeding oesophageal varices. Indeed the first controlled studies of endoscopic injection sclerotherapy, started in the Unit back in 1973, had a major influence on this technique becoming standard practice. The importance of this area was recognised in 1986 by the appointment of David Westaby as consultant physician and the Unit's endoscopist.

Designation of the Liver Failure Unit as a supra-regional/national centre by the Department of Health, with centrally protected funding, came in 1986. The joint programme of liver transplantation with Cambridge had been recognised by a similar designation the previous year and, with the increasing numbers of such operations being performed at King's, the Liver Unit was accorded the status of an independent centre for liver transplantation in October 1989.

Roger's election to the membership of the Saints and Sinners Club of London, brought many new friends to the Unit. This open hearted group of extroverts generously supported the building of a special transplant suite adjacent to Todd ward and the refurbishment of some of the more heavily used ward areas. At this time also, The Special Trustees of King's provided for the conversion of a property made available by Camberwell Health Authority on the King's site into a 'half-way house' for the longer term postoperative care of transplant recipients - the first such community development by the Health Authority.

Today, there are few remnants of the heady days of the Unit's genesis. Many of those mentioned above and others who worked closely with Roger during its early development, including Ian Dymock, Peter Golding, John Hunter, Douglas Maxwell, Iain Murray-Lyon, Mark Rake, Martin Smith and Robin Walker, to name but a few, have long since moved on exhausted to more comfortable pastures. The boss has become ' $R W$ ', in deference to one who is beginning to accept his role of elder statesman. Junior clinicians no longer consider it essential to profess an interest in sailing to secure an appointment on the Unit and, now that RW is allowed to fly the White Ensign, those who do crew on 'Jos of Hamble' often do not even have to provide their own beer.

Gone is the 'smelly office' - the cubbyhole that 
housed the senior lecturers - so dubbed because of David Silk's penchant for removing his shoes. Gone, too, are the Saturday 'morning' rounds, which were started at Dulwich and went on so long as to prompt the exasperated wife of one senior registrar to telephone midafternoon and, with no attempt at finesse, inform Roger that her husband's lunch had been reduced to a burnt offering - an action that had an unexpectedly immediate beneficial effect on her husband's career (a consultancy elsewhere was quickly arranged). It was during one of these rounds that Bob Bailey, newly arrived from Canada and finding no one in the laboratories, spoke those now immortal words: 'Where's the big howdy?'.

At the present time, the Liver Unit has a staff complement of 140 (including house officers, nurses, and administrative and clerical grades), of which 44 are clinicians of registrar grade or higher and 28 are graduate scientists (10 postdoctoral), who together deal with the large clinical workload and contribute to the research and development programme on a full or part time basis. There is an annual turnover of about $20 \%$ of staff, which guarantees a continuing supply of fresh blood (in more than one sense), but Roger Williams has always believed that success depends on an element of stability and continuity and, to this end, has made strenuous efforts to retain a core of key members. Currently, about a third of the staff have been with the Unit for 10 years or more, and he is beginning to remember some of their names.

It is impossible to identify here all those who have passed through the Liver Unit during the last 25 years, but we remember John Winch, who (uniquely) had held a senior lectureship in surgery on the Unit during the early days of the extracorporeal animal liver perfusion studies and who sadly died in a boating accident some years ago. Equally poignantly, we remember Brian Macdougall, a much loved and respected clinical research fellow and later senior registrar who went on to become a consultant physician at the Royal Sussex County Hospital in Brighton, who tragically passed away last year after a short illness.

Over the years, the Unit has attracted 145 clinicians from 40 countries overseas to do research and receive postgraduate training in hepatology. In addition, a total of 69 British clinicians have moved on to take up appointments as consultant physicians or equivalent posts elsewhere in the United Kingdom and 21 basic scientists who have passed through the Unit now hold senior appointments in academic units or in industry in the United Kingdom and abroad. These various groups, together with a number of other individuals who have remained in the Unit, account for the 54 PhDs, MDs and other higher degrees awarded to Liver Unit members.

Apart from its teaching and postgraduate training activities, the Unit has contributed to the academic life of King's in many other ways. It has organised seven major conferences on various aspects of liver disease, published some 850 original papers and numerous other articles and, in 1973, RW started the first annual, week long, residential course in liver disease, which has continued under the auspices of the British Postgraduate Medical Federation and attracts more than forty clinicians each year from the United Kingdom and abroad. At Roger's insistence, the course is traditionally held during the week leading up to Christmas, to ensure that Unit staff do not develop a habit of 'sloping off' early in the festive season. Important links have been forged with other centres in the United Kingdom, including Professor Arie Zuckerman's laboratories at the London School of Hygiene and Tropical Medicine (now at the Royal Free Hospital and Medical School), as well as abroad - notable among which has been a major collaboration with Professor Neils Tygstrup and the University of Copenhagen in a number of international multicentre drug trials.

As noted elsewhere in this issue, progress in the field of liver transplantation, in the management of acute liver failure and of oesophageal varices, and in drug therapy in various chronic liver diseases and hepatocellular carcinoma, is continuing to be made. In addition, with the increasing application of new techniques in cell biology and molecular biology, developments are proceeding apace in immunogenetics, hepatic malignancy, drug metabolism, coagulopathy, cellular iron metabolism, and in the cellular and humoral immunology of autoimmune liver disease and viral hepatitis.

The captain's hand is still firmly on the tiller, but the size of the Unit has necessitated some devolution of responsibility and internal specialisation and, for running the clinical and research activities of the Unit on a day-to-day basis, he is now variously assisted by the senior staff mentioned above and by the assistant director of the Sheik Zaid Centre (Philip Johnson), three clinical senior lecturers (Adrian Bomford, Graeme Alexander, and John O'Grady) and the senior postdoctoral scientists (Robin Hughes, Mike Tredger, Peter Langley, Barbara McFarlane, and Christopher Gove).

No history of the Liver Unit would be complete without mention of the nursing staff, many of whom have their own interesting tales to tell. The contribution made by this dedicated band, of which Sister Gladys (probably the first specialist 'liver nurse' in the country) was the pioneer, is incalculable. Some of her immediate successors, are still with the Unit, including Sisters Rosemary and Francesca (now Transplant Coordinator), and Helen and Mary who are running the new ENB-recognised specialist liver nursing course (another 'first') - the realisation of which had been one of Roger's long cherished hopes. The many others are fondly remembered.

With progress comes change. The 'Liver Unit' is no more. Last year it became The Institute of Liver Studies, with a separate Board of Management answerable to the Delegacy of King's College School of Medicine and Dentistry and to Camberwell Health Authority - a move approved by the Delegacy on the recommendation of the Faculty Board, and one that should further increase collaboration between the Medical School and the School of Life, Basic Medical and Health Sciences. This year has seen the expansion of the Liver Failure Unit to a 
five bed intensive care facility (made possible through a major capital grant from the Department of Health), and the conversion of part of the laboratories into the Maurice Wohl Unit for Molecular Biology in Liver Disease - a joint venture with the Medical School, linked with the School's main molecular biology Unit. It is doubtful if Roger Williams will ever rest on his laurels and we can look forward with certainty to further chapters in the story of 'The Institute of Liver Studies'.

1 Smith PM, Studley F, Williams R. Assessment of body iron stores in cirrhosis and haemochromatosis with the differential ferrioxamine test. Lancet 1967; i: 133-5. 